\title{
Velocity Boundary Layer Analysis of a Flat Plate Heat Exchanger in Laminar Flow: A Case Study
}

\author{
Mojtaba \\ Mirdrikvand \\ Research Center of \\ Petroleum \\ University of \\ Technology \\ Mirdrikvand@ \\ gmail.com
}

\author{
Behrooz \\ Roozbehani \\ Research Center of \\ Petroleum \\ University of \\ Technology \\ roozbehani.behrooz \\ @gmail.com
}

\author{
Saeedeh Imani \\ Moqadam \\ Research Center \\ of Petroleum \\ University of \\ Technology \\ saeedeh.imani@ \\ gmail.com
}

\author{
Ali Cheshmeh \\ Roshan \\ Research Center of \\ Petroleum \\ University of \\ Technology \\ mojtaba_pop@ \\ yahoo.com
}

\author{
Yasin Ramezani \\ Petroleum \\ University of \\ Technology \\ yasin.ramezani@ \\ put.ac.ir
}

\begin{abstract}
In this article, a behavioral analysis of velocity boundary layer in a flat plate heat exchanger in laminar flow condition through CFD simulation using FLUENT software is done. The main objective of this study is to determine the velocity vectors between the flat plates of the heat exchanger. In addition, wake occurrence, differences of velocity at different surfaces between plates, angles of velocity vectors and the effect of wake phenomenon on the shear stresses exerted on the plates are discussed in detail. The study graphically illustrates results based on fluid's behavior by a 3D and 2D simulation with air and water as cold and hot streams that affect plate's situation and its hydro dynamical operations. Consequently, some important design features regarding wake point occurrence and pressure loss are investigated. In addition, eddy current and reverse flows in the wake area and the angles of the velocity vectors are described.
\end{abstract}

Keywords- Flat Plate Heat Exchanger; wake; boundary layer; velocity; FLUENT; CFD

\section{INTRODUCTION}

Plate heat exchangers (PHEs) are among the most applicable thermal facilities in diverse industries, particularly in oil and gas operations [1, 2]. Due to their high thermal efficiencies, PHEs are widely used in industries.

Plate heat exchangers are mainly made of thin plates that are pressed into a whole frame and shaped in a package. They are designed in various types based on which the plates might be flat or curved with different angles according to their applications [3, 4]. PHEs are much more sensitive to temperature and pressure than other heat exchangers. Their sensitivity is due to their structures that are mainly specified by plate perforations and gasket designs $[3,5]$.

An accurate modeling of the PHE not only simplifies fluid flows study and velocity governing equations but is also significant for proper equipment evaluation and design [6-7].

Computational Fluid Dynamics, briefly recognized as CFD, technically models fluid behavior using computer simulation. Referring to growth and establishment of computer programing in engineering science, development of CFD software packages is implemented to simulate complex pragmatic flow simulation. In a computational characterizing of flow behavior, mathematical equations that approve the flow dynamics roles are used to attain a proper treatment of flow.

Therefore, Computational Fluid Dynamic (CFD) methods are used to model PHEs. In a CFD modeling, computational algorithms are used to model heat, mass, and momentum transfer [8]. It brings a rapid solution for designing and optimizing heat exchangers [9]. Small cells are used to estimate the geometrical shape [10]. Considering grids and boundary condition restrictions and implementing numerical solving methods help finding velocity boundary layers and analyzing them [11].

A simulation of a flat PHE on plate surfaces has been investigated in this study in order to analyze velocity boundary layer using FLUENT [16]. The occurrence of the wake phenomenon and its influence on shear stresses that are exerted on plates are discussed in detail and illustrated graphically [18, 19]. This study was conducted to simulate a flat PHE in the Research Center of Abadan Institute of Technology, with dimensional features shown in Table I, constructed from May 2010. The results of this paper are going to estimate the process conditions, and also the velocity boundary layers of the heat exchanger.

\section{A. Using CFD for boundary layer analysis}

The basis of computational fluid dynamics, is solving fluid problems by using numerical methods to convert the partial differential equation to numerical equation. Two numerical methods can be used for solving: FVM (finite volume method) or FEM (finite elements method) [12].

\section{B. Finite volume method}

The finite volume method is a method for representing and evaluating partial differential equations in the form of algebraic equations $[13,15]$. FVM refers to small volume surrounding each node point of a mesh. In the finite volume method, volume integrals in a partial differential equation that contain a divergence term are converted to surface integral, using the divergence theorem [17].

These terms are then evaluated as fluxes at the surface of each finite volume; these methods are conservative. Another 
advantage of the finite volume method is that it is easily formulated for unstructured meshes. It is much easier to capture (as well as numerically possible) the characteristic nature of hyperbolic equations in FVM using flux split schemes, upwinding etc. [14, 15].

TABLE I. PLATE'S MAIN DIMENSIONS

\begin{tabular}{cc}
\hline Dimension & Value \\
\hline Plate height, $(\mathrm{mm})$ & 550 \\
Plate thickness $(\mathrm{mm})$ & 1.0 \\
Distance between plates $(\mathrm{mm})$ & 5.0 \\
Height of channel $(\mathrm{mm})$ & 63.5 \\
Heat transfer area $(\mathrm{m} 2 / \mathrm{plate})$ & 0.0635 \\
Distance between channels & 40 \\
\hline
\end{tabular}

\section{SiMULATION}

The first step of a CFD simulation must be completed by mesh generation, which is the geometrical restriction that satisfies the equations for heat transfer and momentum transfer $[13,15]$. Hot fluid enters from top left channel of Figure 1 and cold fluid enters from right bottom channel. The number of meshes reported from the software is 37240 , created with the software GAMBIT.

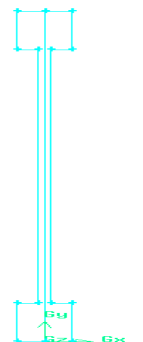

Fig. 1. GAMBIT a) unmeshed shape

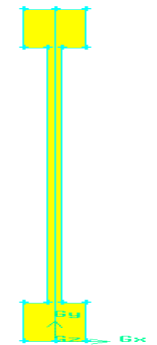

b) GAMBIT meshed shape

\section{A. Using Air as a hot and cold flow 3-D shape}

Plate's Dimension is $X=220 \mathrm{~mm}, Y=550 \mathrm{~mm}, \mathrm{Z}=20 \mathrm{~mm}$ and the area of one $0.24 \mathrm{~m}^{2}$ area channel is $0.0036 \mathrm{~m}^{2}$, sectional area is $0.004 \mathrm{~m}^{2}$ and flow air velocity is about 0.05 $\mathrm{m} / \mathrm{s}$.

\section{B. Results and Discussion}

The problem was numerically solved using the finite volume method [12] with FLUENT 6.3.26. The simulations were carried in a core 2 Duo CPU with 2 GB RAM. By using 2 ddp mode and implicit formulation and considering pressure based solver by momentum and energy discretization in 2 dimensional space, it implies a 5000 number of iterations and 1e-06 residual. When fluid passes through the plates, the pressure decreases, this is due to head loss, as shown in Figures 3(a) and 3(b) [20].

The color of hot flow input is orange but the color of hot flow output is blue, this shows that the pressure has been decreased (the magnitude of the figure is in gage). Steady flow enters the channel but at the exit eddy current is produced, due to shear stresses and wake. In Figure 6 eddy current is shown.

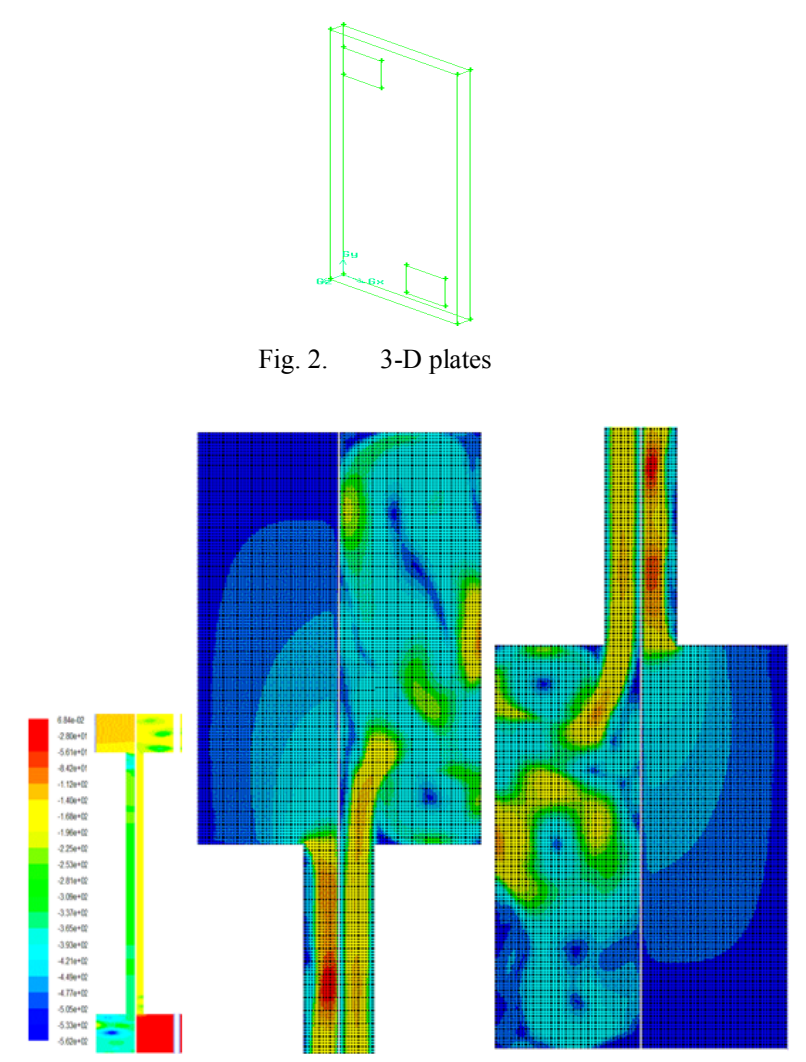

Fig. 3. a) Contour of pressure (pa) b) Eddy current at the exit of hot \& cold flow

At flow entrances the channel area is $0.0635 \mathrm{~m}^{2}$, but between the plates the cross sectional area is $0.005 \mathrm{~m}^{2}$, so the cross sectional area has been decreased, which causes an increase in flow velocity, as shown in Figure 5.

The shear stresses are exerted to the fluid by the wall. The velocity of a layer in contact with the wall is zero, and increases with $d$ (distance from the wall). In Figures 5 and 6 the magnitude of velocity near the plate is low, whereas far from the plate is high.

At $X=0$, velocity is zero because the layer of fluid is connected with the plate. Between $X=0.002$ and $X=0.003$ the magnitude of velocity is maximum because it is placed as far as possible from adjacent plates.

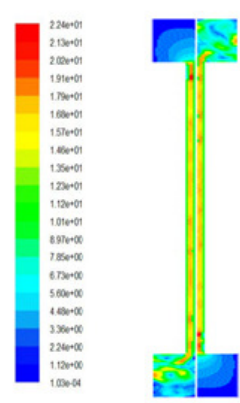

Fig. 4. Contour of velocity $(\mathrm{m} / \mathrm{s})$ 


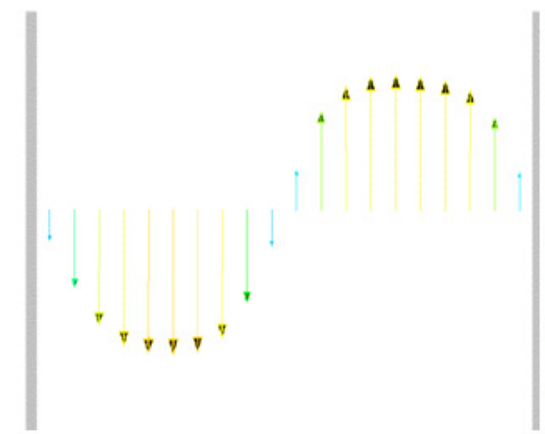

Fig. 5. Velocity vectors between plates
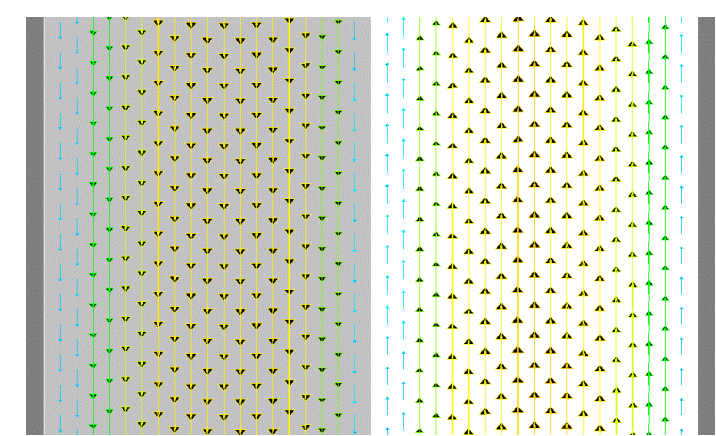

Fig. 6. Velocity vectors at cross section of the plates

TABLE II. VELOCITY MAGNITUDES AT DIFFERENT DIFFERENCES

\begin{tabular}{cccc}
\hline $\begin{array}{c}\text { Surface } \\
\text { Vertex } \\
\text { Value } \\
(\mathbf{m})\end{array}$ & $\begin{array}{c}\text { Velocity } \\
\text { Magnitude } \\
(\mathbf{m} / \mathbf{s})\end{array}$ & $\begin{array}{c}\text { Surface } \\
\text { Vertex } \\
\text { Value } \\
(\mathbf{m})\end{array}$ & $\begin{array}{c}\text { Velocity } \\
\text { Magnitude } \\
(\mathbf{m} / \mathbf{s})\end{array}$ \\
\hline-0.001 & 11.4077 & 0.001 & 11.660 \\
-0.002 & 14.1264 & 0.002 & 14.443 \\
-0.003 & 13.7345 & 0.003 & 14.061 \\
-0.004 & 10.1425 & 0.004 & 10.360 \\
-0.005 & 5.5176 & 0.005 & 1.2882 \\
0 & 0 & & \\
\hline
\end{tabular}

When the magnitude of velocity along a streamline increases, the magnitude of pressure will decrease. This is due to Bernoulli equations. In Figures 7(a) and 7(b), the color of velocity vectors near the channel is red. The color tends to blue at the cross sectional area as the flow, and the magnitude of pressure, decreases.

As illustrated in Figure 7, 'wake' occurs near the right wall. The direction of some vectors near the right wall is downward and the angle of vectors varies from $-180^{\circ}$ to $180^{\circ}$.

\section{2-D Plates... fluid: water: Assumption in FLUENT}

Assumptions used in this study are the same as in the previous section. Wake occurred in cold output and near the wall is shown in Figures 8 and 9. According to Figures 10(a) and 10(b), the magnitude of pressure through the plates decreases. The magnitudes of the velocity between plates increases compared with internal channel velocity.
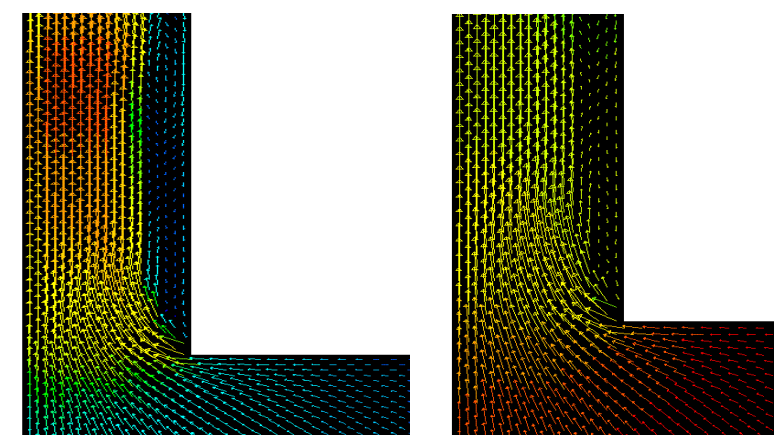

Fig. 7.

a) velocity vector

b) pressure vectors

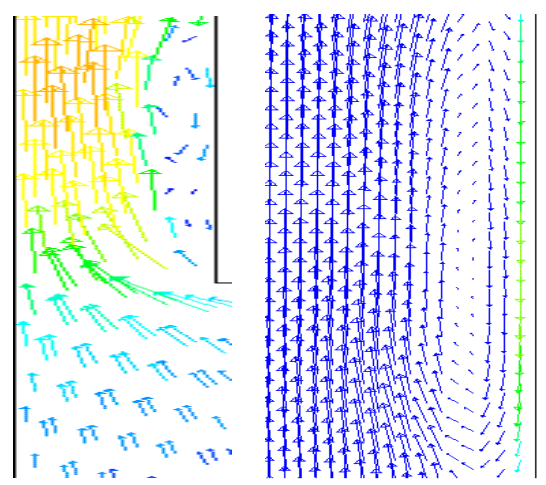

Fig. 8. Wake occurred in cold output

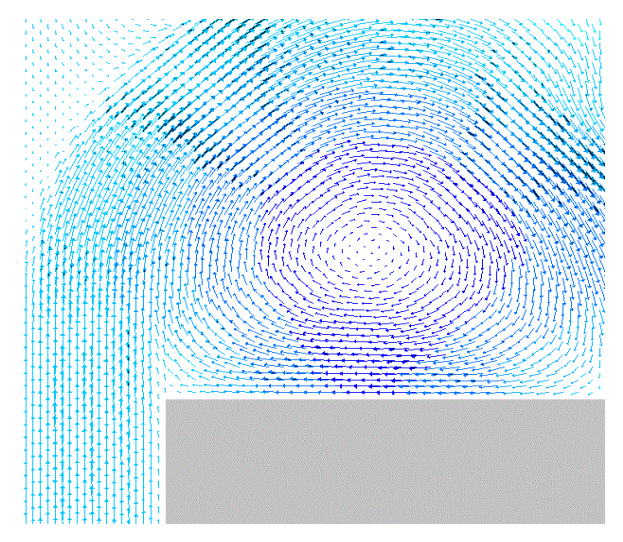

Fig. 9. Wake occurred near the wall
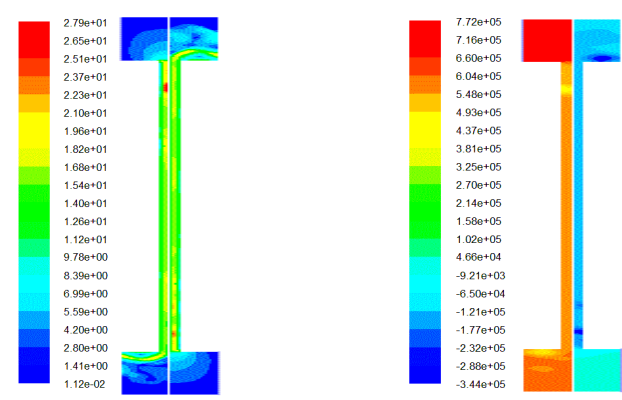

Fig. $10 . \quad$ a) Velocity contour $(\mathrm{m} / \mathrm{s}) \quad$ b) Pressure contour $(\mathrm{Pa})$ 
Now we want to compare the velocity magnitude near the plate and far from the plate. Figure 11 shows velocity magnitude vs. $\mathrm{y}$ at $\mathrm{x}=0.0002 \mathrm{~m}$, and Figure 12 shows velocity magnitude at $\mathrm{x}=0.0025$ (exactly at the middle of the plates). Average velocity at $x=0.0002 \mathrm{~m}$ is equal to $4.73 \mathrm{~m} / \mathrm{s}$ while the average velocity at $\mathrm{x}=0.0025 \mathrm{~m}$ is equal to $12.7 \mathrm{~m} / \mathrm{s}$.

Due to wake, the angle of vectors varies from -180 to 180 near the wall, as shown in Figure 12 and 13, the angle of vectors in range $[y=0.0635, y=0.175]$ is so various.

Due to the wake phenomenon, wall shear stress in $\mathrm{Y}$ ranges $[0.0635,0.175]$ has vibration values. In range $\mathrm{Y}[0,0.0635]$ and $\mathrm{Y}[0.4865,0.55]$ there is no wall so the shear stress is equal to zero.

\section{D. (3-D plates.... fluid: air)}

Using FLUENT in 3ddp mode and implicit formulation for steady state laminar flow and also pressure based solver in a 3D space, first order upwind solution for momentum discretization gives Number of iteration $=350$ and Residual $=1 \mathrm{e}-$ 07. Walls are located at $\mathrm{z}=0$ and $\mathrm{z}=0.02 \mathrm{~m}$, near the walls velocity magnitudes are low due to viscous fluid flow or shear stresses, as shown in Figure 14.

From Figure 14 we understand that the magnitude of velocity increased from $\mathrm{z}=0$ to $\mathrm{z}=0.01 \mathrm{~m}$ and decreased from $\mathrm{z}=0.01$ to $\mathrm{z}=0.02 \mathrm{~m}$. Figure 14 shows the average magnitude of velocity at different surfaces from $z=0$ to $z=0.02 \mathrm{~m}$. Maximum velocity is reached at $\mathrm{z}=0.01$.

Based on Table III, at surface $z=0$ fluid is in contact with the plate so the velocity of the fluid is zero and the color of the surface is blue. The velocity increases as $\mathrm{z}$ increases from 0 to $0.01 \mathrm{~m}$, so the color of the surfaces tends to red, then velocity decreases as $\mathrm{z}$ increases from $0.01 \mathrm{~m}$ to $0.02 \mathrm{~m}$ so the color of surface tends to blue.

TABLE III. CONTOUR OF VELOCITY AT DIFFERENT SURFACES FROM SURFACE $Z=0$ TO SURFACE $Z=0.02 \mathrm{M}$

\begin{tabular}{cccc}
\hline $\begin{array}{c}\text { Surface } \\
\text { vertex } \\
\text { value }(\mathbf{m})\end{array}$ & $\begin{array}{c}\text { Velocity } \\
\text { magnitude } \\
(\mathbf{m} / \mathbf{s})\end{array}$ & $\begin{array}{c}\text { Surface } \\
\text { vertex } \\
\text { value }(\mathbf{m})\end{array}$ & $\begin{array}{c}\text { Velocity } \\
\text { magnitude } \\
(\mathbf{m} / \mathbf{s})\end{array}$ \\
\hline 0.001 & 0.01238 & 0.013 & 0.0513 \\
0.003 & 0.003188 & 0.017 & 0.04359 \\
0.005 & 0.04482 & 0.019 & 0.03171 \\
0.007 & 0.05257 & 0 & 0 \\
0.009 & 0.05591 & Net & 0.03732 \\
0.011 & 0.05591 & & \\
\hline
\end{tabular}

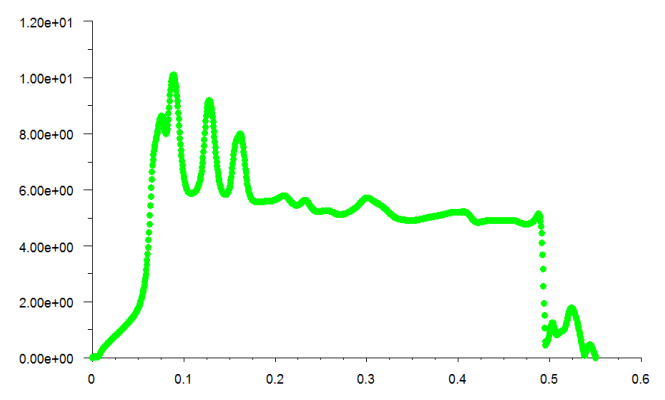

Fig. 11. Velocity magnitude at $\mathrm{x}=0.0002 \mathrm{~m}$

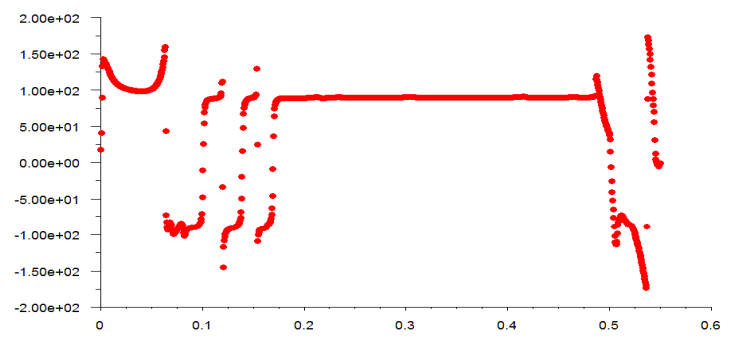

Fig. 12. Angles of vectors versus y

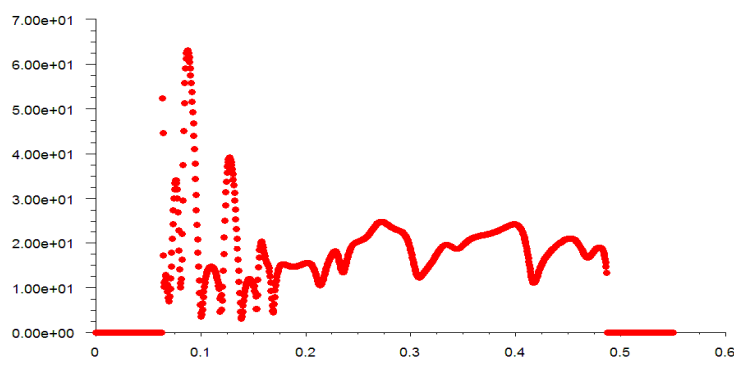

Fig. 13. Wall shear stresses versus y
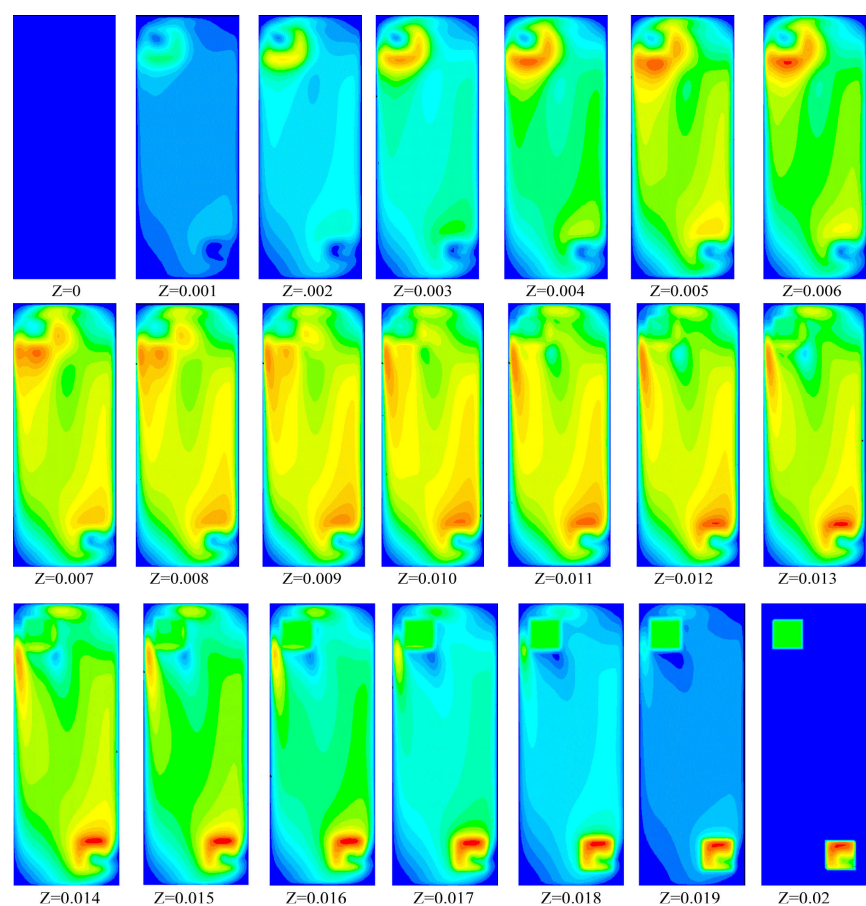

Fig. 14. Contour of velocity at different surfaces from surface $\mathrm{z}=0$ to surface $\mathrm{z}=0.02 \mathrm{~m}$

At $\mathrm{z}=0.02 \mathrm{~m}$, steady flow enters from the top channel so the color of the inlet channel is uniform green but in the outlet channel the flow is not uniform and exits with different velocities so the color of the outlet channel varies from green to red. Based on Table III, the average velocity of fluid at surfaces near the wall changed more rapid than at surfaces far from the wall. 


\section{CONCLUSION}

1. The pressure of fluid decreases through the flow due to energy losses.

2. Wake phenomenon occurs when the flow reaches the edge of the plate that is not located in the same direction as the flow.

3. Due to the existence of the wake phenomenon it is better to install instruments measuring pressure, temperature, and other measuring devices away from the wake area.

4. Due to the existence of the wake phenomenon and forces exerted on the wake area, the probability of corrosion increases. Therefore, the thickness of the walls should be inspected regularly.

5. Eddy current and reverse flows occur in the wake area so the angles of velocity vectors have -180 to 180 degrees variation from the direction of the flow.

6. The magnitude of velocity near the walls is smaller compared to areas far from the walls due to shear stresses exerted from the wall to the fluid.

7. By using CFD method we can design a shape for the PHE that has less pressure losses.

8. By using CFD method we can design a more efficient plate heat exchanger

9. FLUENT software is suitable to analyze the behavior of the flow in a process or apparatus.

\section{REFERENCES}

[1] K. Grijspeerdt, B. Hazarika, D. Vucinic, "Application of computational fluid dynamics to model the hydrodynamics of plate heat exchangers for milk processing", Journal of Food Engineering, Vol. 57, No. 3, pp. 237242, 2003.

[2] I. M. Afonso, L. Hes, J. M. Maia, L. F. Melo, "Heat transfer and rheology of stirred yoghurt during cooling in plate heat exchangers", J. Food Eng., Vol. 57, pp. 179-187, 2003.

[3] W.W. Focke, J. Zachariades, I. Olivier, "The effect of the corrugation inclination angle on the thermohydraulic performance of plate heat exchangers", Int. J. Heat Mass Transfer, Vol. 28, No. 8, pp. 1469-1475, 1985.

[4] G. Zhang, M. Tian, S. Zhou, "Simulation and analysis of flow pattern in cross-corrugated plate heat exchangers", Journal of Hydrodynamics Ser.B, Vol. 18. No. 5, pp. 547-551, 2006.

[5] J. A. W. Gut, J. M. Pinto, "Optimal configuration design for plate heat exchangers", International Journal of Heat and Mass Transfer, Vol. 47, No. 22, pp. 4833-4848, 2004.

[6] B. P. Rao, P. K. Kumar, S. K. Das, "Effect of flow distribution to the channels on the thermal performance of a plate heat exchanger", Chemical Engineering and Processing, Vol. 41, No. 1, pp. 49-58, 2002

[7] F. A. Tereda, N. Srihari, S. K. Das, B. Sunden. "Experimental study on port to channel flow distribution of plate heat exchangers", Proceedings of the Fifth International Conference on Enhanced, Compact and UltraCompact Heat Exchangers, pp. 208-214, USA, 2005.

[8] M. V. De Bonis, G. Ruocco, "Conjugate fluid flow and kinetics modeling for heat exchanger fouling simulation", International Journal of Thermal Sciences, Vol. 48, No. 10, pp. 2006-2012, 2009

[9] X. H. Han, L. Q. Cui, S. J. Chen, G. M. Chen, Q. Wang, "A numerical and experimental study of chevron, corrugated-plate heat exchangers", International Communications in Heat and Mass Transfer, Vol. 37. No. 8, pp. 1008-1014, 2010.
[10] J. Ding, R. M. Manglik, "Analytical solutions for laminar fully developed flows in double-sine shaped ducts", Heat Mass Trans., Vol. 31, No. 4, pp. 269-277, 1996.

[11] J. C. Leuliet, J. F. Maingonnat, M. Lalande, "Thermal behaviour of plate heat exchangers with Newtonian and non-Newtonian fluids", in: Proceedings Congres Eurotherm 5 et $1 \mathrm{er}$ Colloque TIFAN, Compiegne, pp. 1-15, 1988.

[12] J.C. Leuliet, J .F. Maingonnat, M. Lalande, "Etude de la perte de charge dans des echangeurs de chaleur a plaques traitant des produits nonnewtoniens”, Rev. G en. Therm., Vol. 308-309, pp. 445-450, 1987.

[13] F. Delplace, J. C. Leuliet, "Generalized Reynolds number for the flow of power law fluids in cylindrical ducts of arbitrary cross-section", The Chemical Engineering Journal and The Biochemical Engineering Journal, Vol. 56, No. 2, pp. 33-37, 1995.

[14] M. M. A. Bhutta, N. Hayat, M. H. Bashir, A. R. Khan, K. N. Ahmad, S. Khan, "CFD applications in various heat exchangers design: A review", Applied Thermal Engineering, Vol. 32, pp. 1-12, 2012.

[15] G. Taylor, "Dispersion of soluble matter in solvent flowing slowly through a tube", Proc. Roy. Soc. Lond. A, Vol. 219, No. 1137, pp. 186$203,1953$.

[16] B. Xia, D. -W. Sun, "Applications of computational fluid dynamics (CFD) in the food industry: a review", Computers and Eletronics in Agriculture, Vol. 34, pp. 5-24, 2002.

[17] S. Jain, A. Joshi, P. K. Bansal, "A new approach to numerical simulation of small sized plate heat exchangers with chevron plates", Journal of Heat Transfer, Vol. 129, No. 3, pp. 291-297, 2007.

[18] M. A. Mehrabian, R. Poulter, "Hydrodynamics and thermal characteristics of corrugated channels: computational approach", Appl. Math. Modell., Vol. 24, No. 5-6, pp. 343-364, 2000.

[19] M. Ciofalo, J. Stasiek, M. W. Collins, "Investigation of flow and heat transfer in corrugated passages-II. Numerical simulation", Int. J. Heat Mass Transfer, Vol. 39, No. 1, pp. 165-192, 1996.

[20] POLYFLOW 3.9 User's Guide, Fluent Inc., Lebanon, USA, 2001. 